\title{
Unraveling the Geological History of the Fenelon Gold Property
}

\author{
JOY M CARTER* AND DANIEL D GREGORY
}

University of Toronto, Toronto, ON, M5S 3B1, Canada

(*correspondence: Joy.carter@mail.utoronto.ca)

(Daniel.gregory@utoronto.ca)

The Abitibi Greenstone Belt is the most important gold producing area in Canada and one of the most important globally. The Fenelon Property, a gold deposit in the northern Abitibi, is the focus of this research project. It is located in west-central Quebec, in the northern Abitibi Greenstone Belt, proximal to the Sunday Lake Deformation Zone ("SLDZ") which hosts the Detour Gold Mine in Ontario, and Balmoral Resources' gold deposit at Martinière. Secondary splays of the SLDZ transect the Property over two to four-kilometer strike lengths and have controlled the emplacement of a significant gold system along the Jeremie Pluton and within a mafic-ultramafic sill referred to as the Main Gabbro.

However little research both on the age of the rocks and the evolution of the host intrusive has been conducted, resulting in a lack of understanding of the underlying geology of the area. In this study we use a combination of zircon geochronology, whole rock geochemistry and detailed petrography to improve the understanding of the intrusive units that represent the main host lithologies to the gold mineralization at the Fenelon Property. These data will be used to compare the Fenelon geology to that which hosts mineralization found elsewhere in the Abitibi and will facilitate the identification of new exploration targets in the northern Abitibi. 